\title{
Das stille Lesen
}

Liebe Leserinnen, liebe Leser,

im frühen und hohen Mittelalter war mit dem Lesen nicht allein das Auge sondern auch das Ohr befasst. Es wurde laut gelesen, allein schon deshalb, weil die anderen nicht Lesen konnten und nur Gesprochenes verstanden. Lesen bedeutete grundsätzlich: laut lesen. ${ }^{1}$ Auch wenn der Leser allein war, mochte er sich das Gelesene vorsprechen, um es mit dem geübteren Sinnesorgan aufnehmen zu können. Nur die Kopisten in den Klöstern des frühen Mittelalters lasen ihre Texte still und setzten visuelle Reize unmittelbar in Schrift um. Ansonsten gab es bis etwa Mitte des 12. Jahrhunderts in der Regel nur lautes Lesen. Danach setzte an den Universitäten die Gewohnheit ein, still zu lesen; im 15. Jahrhundert war das bei den Gebildeten bereits die Regel; aber noch im 19. Jahrhundert ging vielen Menschen - zumal den schreibunkundigen - die Fähigkeit zum stillen Lesen ab. Das stille Lesen - heute die Regel - brauchte also Jahrhunderte, um sich durchzusetzen.

Das stille Lesen ist naturgemäß keine kollektive Angelegenheit. Der stille Leser muss sich auf das Gelesene konzentrieren, um es zu verstehen. Er und das Gelesene stehen sich ohne einen Dritten gegenüber. Der Leser erfühlt sich als Individuum. Dazu kommt: Im Mittelalter las er in der Regel um seines Seelenheils willen geistliche Texte. Er sah sich so für das Jüngste Gericht vor, vor dem er als Individuum allein stehen würde. Das war zwar nicht neu, neu war aber die Konsequenz, die Hinwendung zur Individualität. Diese zeigt sich z.B. auch darin, dass um diese Zeit die Kirche an Stelle der laut gesprochenen kollektiven Beichtrituale die Gewissenserforschung und die Ohrenbeichte einführte.

Das stille Lesen führte weiterhin dazu, dass adelige Herren und später auch begüterte bürgerliche Patrone Bücher sammelten und sich im privaten Heim an ruhiger Stelle eine Bibliothek einrichteten. Sie war niemandem sonst frei zugänglich. In sie zog man sich zurück, wenn man ungestört sein wollte. Dort führte man das Hauptbuch aber auch sein Tagebuch und brachte die Sammlung von persönlichen Erinnerungs- und Kunstgegenständen unter. So wurde die Bibliothek zum Inbegriff des Privaten, in dem man auch persönliche Geheimnisse verbergen konnte. Sie war das Vorbild für das Studio und weitere Rückzugsräume. Diese Entwicklung zu Individualität und Privatheit hatte sich aus der Umstellung auf stilles Lesen ergeben; sie hat inzwischen neun Jahrhunderte lang angehalten und mag auch mit der Datenschutzgesetzgebung noch nicht abgeschlossen sein.

Damit hatte sich in der Renaissance eine neue Bedeutung des Begriffs „privat" eingestellt. Er stammt aus dem alten Rom. Ursprünglich war dort alles Land öffentlich gewesen. Immobiles Eigentum, das dem öffentlichen Bereich "entrissen“ (von "privare“, rauben, entreißen) worden war, galt als „privatum“. Noch im fränkischen Reich hatte es diese Bedeutung für das " allod", den privaten Beuteanteil am eroberten Land (neben dem „Ilehen", dem von einem Fürsten gewährten Besitz). Mit der Individualisierung hat es darüber hinaus die neue Bedeutung hinzugewonnen.

Bemerkenswert erscheint mir, liebe Leserinnen und Leser: Leitet sich die ursprüngliche Bedeutung von „privat" von einer spontanen Freiheit-zu ab, die sich das Individuum nimmt, um sich öffentliches Eigentum anzueignen, so ist die andere Bedeutung, die es seit der Renaissance hinzubekommen hat, die einer rezeptiven Freiheit-von, in diesem Falle von Ungemach durch die Zudringlichkeit des Kollektivs. Es hat sich ein Privatbereich ergeben, den es vor dem Kollektiv zu schützen gilt. In ihm will man ungestört allein sein können. Man sucht das, was im Englischen als „Right to be Left Alone“ bezeichnet wird. Bezeichnend für den hier aufgezeigten historischen Wandel ist: Allein sein zu können, mag heute begehrenswert sein, der laut lesende mittelalterliche Mensch hingegen lebte immer noch kollektiv und fürchtete nichts mehr als den Teufel und das Alleinsein!

Mit freundlichen Grüßen, Ihr

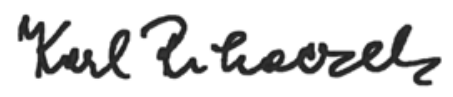

1 Aus Roger Chartier, Praktiken des Lesens, in Philippe Aries und Georges Duby (Hg), Geschichte des privaten Lebens, p 128 ff, S. Fischer 1986 